\title{
Masculinity in Selected L-Men Advertisements
}

\author{
Albertus Sebastian Adi Prasetyo \\ English Department, Faculty of Languages and Literatures, Petra Christian University, Siwalankerto 121- \\ 131, Surabaya 60236, INDONESIA \\ Email: m11415018@john.petra.ac.id ; sebastianadi20@gmail.com
}

\begin{abstract}
This study analyzes how L-Men persuades its target market to buy its products through the use of a masculinity image in its two advertisements. The two advertisements which the writer studied are entitled "L-Men 2018: 2Go \& Gain Mass: Men's Guide" and "Iklan L-Men Gain Mass Terbaru 2014 Versi Albert Sultan". In order to find out how masculinity is portrayed in the two advertisements, the researcher sets his analysis on the advertisements' verbal and non-verbal expressions. In so doing, the researcher conducts his analysis using the theory of Multimodal Discourse Analysis. Within the findings, it is revealed that despite both advertisements are indeed portraying masculinity, how each advertisement shows what is seen as masculine is different from one another. One advertisement shows that masculinity is based on a man's aesthetical appearance and the other advertisement shows that masculinity is based on the physical strength of a man.
\end{abstract}

Keywords: Multimodal Discourse Analysis, Masculinity, Advertisement, L-Men

\section{INTRODUCTION}

Advertisement is not less important than employees in businesses. Because of advertisement, producers are able to sell their products as advertisements are "intended to promote the sale of specific commodities" (Danesi, 2004, p. 256). One of the many ways to create an advertisement is through employing modes or semiotic resources. Modes or semiotic resources, according to Kress, are socially shaped and culturally given resources for making meaning (Kress, 2010, p. 8). Thus, the use of different kinds of modes or semiotic resources may catch the attention a certain group of people which is exactly what an advertisement should aim for. The usage of these semiotic resources may also create an advertisement that is not only creative but also meaningful. Since advertisements are meaningful and now more creative, it is possible to turn advertisments into a field of discourse on their own. As Cook (2001, p. 220) mentions, advertisements are open to interpretation as the value taken from the advertisement is different for each individual. Thus, in this study, the researcher is interested to explore the meanings which contained in several creative advertisements.

Some of the meaningful advertisements that are creative in exploring modes are the L-Men Gain Mass advertisements series. Using modes, the L-Men through the Gain Mass advertisements series, namely "L-Men 2018: 2Go \& Gain Mass: Men's Guide" and "Iklan L-Men Gain Mass Terbaru 2014 Versi Albert Sultan", are able to show off image of masculinity. These two advertisements are using the image of masculinity to indirectly sell L-Men's products show by showing its target market the value of attaining the masculinity that is idealized by the society. With this in mind, the researcher is interested to know how masculinity is projected by the two advertisements.

In this study, the researcher aims to analyze the image of masculinity that is projected in the two selected L-Men advertisements. In order to help in writer in his analysis, he sets two research questions that will answer the aim of the study. The questions are as follows:

1. How is masculinity projected in the advertisements through verbal expressions?

2. How is masculinity projected in the advertisements through non-verbal expressions? 


\section{LITERATURE REVIEW}

This study employs Multimodal Discourse Analysis theory based Gunther Kress and Theo van Leeuwen's Reading Images (2006) as well as Multimodality (2010) by Gunther Kress himself. However, due to the broad range of semiotic resources available from the two theories, the writer limits his research with only several resources which are applicable to the analysis such as speech, gestures, facial expressions, colors, and image positioning.

\section{Reading Images}

In this book, Kress and van Leeuwen established an idea that visual works also share the same three functions as language which are ideational, interpersonal, and textual. However, instead of calling the functions in the same way that Halliday uses, Kress and van Leeuwen settled with representational, interpersonal, and compositional. In this study, interpersonal function will be the main focus of the analysis due to the semiotic resources applicable to the analysis found within this specific function.

Interactive function is based on the interaction between the producers and the viewers of the image (Kress \& van Leeuwen, 2006, p. 42). Therefore, this function serves to explain the message within images that the producers wanted to convey to the viewers. This can be realized through few semiotic resources such as gaze, distance, and angle.

Gaze is the act of looking directly through someone's eyes. Gaze is divided into two different types that is demand gaze and offer gaze. Demand gaze is enacted when a person in the visuals is looking directly to the viewers eyes. This creates a form of direct address and demand. This gaze can also create a form of "closeness" between the viewers and the person in the visuals (Kress \& van Leeuwen, 2006, p. 117). Offer gaze, on the other hand, is the opposite of demand gaze which means no eye contacts happen between the viewers and the person in the visuals. In this gaze there is no form of "closeness" created and it is the object which the person in the visuals see that functions as the object of contemplation. Thus, this gaze functions to offer the viewers the contemplated object in the visuals (Kress \& van Leeuwen, 2006, p. 116). Distance and angle together can be understood as some sort of image positioning in visual works. Distance itself can show relation between subjects in visual works. The closer the distance is between each subject, the closer it is the relation between each subject. However, for the opposite of this, the further it is the distance between each subject, the farther it is the relation between each subject. Meanwhile, angle is used to show an implied power relation between each subject depending on the point of view. On a high angle, a subject can look imposing which implies it has a power over the other subjects or even the viewers. On the other hand, on low angle the subject is seen smaller and looks to hold less power compared to the one on the high angle (Kress \& van Leeuwen, 2006, p. 128).

\section{Multimodality}

Gunther Kress proposes an idea that linguistic is not the only semiotic resource which is capable to realise communication and meaning-making. According to him, some other resources are also capable of making meaning such as images, colors, gestures, and facial expressions. Using this theory, the researcher aims to reveal the meaning of the semiotic resources which are present in his analysis. The semiotic resources from this theory which are applicable are speech, writing, colors, and gestures.

The interpretation of writing mode or resource can be realized through its lexis, syntax, and grammar. Speech is more or less the same with writing with the only difference being the usage of the loudness or the softness of sound that speech requires (Kress, 2010, p. 80). 
Gestures involve the movement of body such as walking, moving arms, hands, head and even facial expressions. Though, gestures by itself does not contain fixated interpretation as instead of interpretation, gestures invite impressions. It is through these impressions that people become capable of interpreting gestures (Kress, 2010, p. 81).

\section{METHODS}

This research is using the qualitative content analysis by Schreier (2012). Schreier described qualitative content analysis as a way that allows researcher to draw his or her conclusion through interpretation $(2012$, p. 3). Additionally, Schreier mentions that qualitative content analysis allows data to be examined from a specific point of view (2010, p. 4). Since this analysis involves analyzing verbal and non-verbal data, interpretation is heavily needed especially the one from the perspective of masculinity.

The analysis will be done to the verbal and the non-verbal expressions. In the verbal expressions analysis, the researcher dissects the narrations by analyzing each word's definition and meaning. Then, the researcher gives his analysis on how the choice of words presented in the verbal expressions projecting masculinity context. In the non-verbal expressions analysis, the researcher looks up at the semiotic resources or modes, which are limited to gaze, gestures, facial expressions, colors, and positioning) which can project an image of masculinity. Furthermore, in this analysis, the researcher will point out how the image of masculinity projected through the verbal and non-verbal expressions can indirectly persuade the viewers to buy the advertised product.

\section{FINDINGS AND DISCUSSIONS}

This part contains the analysis to show the projection of masculinity within the two L-Men Gain Mass series advertisements entitled "L-Men 2018: 2Go \& Gain Mass: Men's Guide" and "Iklan L-Men Gain Mass Terbaru 2014 Versi Albert Sultan". The analysis itself will be in order of the research questions, that is the verbal expressions analysis first which then followed by the nonverbal expressions analysis. As this is an analysis of advertisements, the researcher will uncover how this projection of masculinity can be appealing towards L-Men targeted market.

\section{Verbal Expressions That Project Masculinity in The First Video Advertisement}

The first video advertisement, entitled "L-Men 2018: 2Go \& Gain Mass: Men's Guide", has four different kinds of narrations which give an implication of masculinity which are as follows;

1. "Jadi cowok millenial, rambutnya harus kekinian" ("in order to be called a millenial male youth, you must have a stylish hair")

2. "Kerjaan? Yang work-life balance" ("A job? It should have the balance between work and life")

3. "Liburan? Yang Instagrammable" ("Going on a vacation? You should go to an Instagrammable location")

4. "Nutrisi? Pilih L-Men" ("Need more nutrition? Choose L-Men")

Kress mentions in his Multimodality that texts, which includes narrations, are made as messages to others $(2010$, p. 159). In this case the message which is that males, specifically millenial males, can be seen as masculine when they care about their aesthetic appearance. This can be seen from the pattern of the narrations. The wording in every narration suggests that the producers are "commanding" the viewers to do certain things which are considered as masculine. This is justified by the use of the word "cowok" which according to Kamus Besar Bahasa Indonesia is referring to a male in his youth. This word is used a form of addressing to 
the viewers, especially millenial male viewers, that in order to be seen as "cowok" they need to do several things first. The first thing they must do is having a stylish hair (rambutnya harus kekinian). While having a stylish hair is stereotypically attributed to females this era suggests otherwise. Nowadays, males are developing "Adonis Complex" (Elliott \& Elliott, 2005, p. 4). This means men are also paying attention to their physical appearance and "re-construct their idea of what it is to be males" (Harrison, 2008, p. 56). Thus, the narrations are making sense that these are truly aimed at millenial males who aspire to be seen as masculine. The second narration create an addressing towards the millenial males that being responsible males will make them look masculine. According to $\mathrm{Ng}$ and Johnson, millenials put a lot of value in leisure (2015, p. 126). However, it is work and not leisure that is expected of a male (Ellemers, 2018, p. 281). That is why, the second narration uses the word "Kerjaan?" (a job ?) to urge the millenial males to be more responsible in order to be seen masculine. This is further justified by "worklife balance" which puts more emphasis on the idea that "being responsible is masculine". "Work" and "life" balance create an implication that millenial male youth needs to have a good time management in which time management itself is a form of responsibility. Thus, the second thing to do in order to be seen as masculine is being responsible. The third narration is, again, used as a form of addressing to the millenial males. "Liburan?" (vacation), according to Kamus Besar Bahasa Indonesia Online, is the period of time when one is "free from work and school". This has an implication of leisure which is exactly what millenials value. Here, the context of the narration takes place when the actor in the advertisements is water skiing in the sea. Using the context where the narration is spoken, it can be understood that having a leisure time or vacation is alright, however, for millenial males to be seen masculine, their choice of vacation needs to be the one that is adventurous. What makes this narration become more meaningful of masculine image is the use of "Instagrammable" word. "Instagrammable" is a term which millenials refer to the action of taking pictures which are deemed worthy of showing off. Thus, the whole third narration implies that millenial males are seen as masculine if they are adventurous and confident. The fourth narration looks a bit like a generic promotional line which functions as a call to action to buy the product. However, this is actually not the case as the fourth narration contains the idea that connects the first, second, and third narrations altogether. "Nutrisi" (nutrition) is a term used to refer to substances which boosts our physical health and energy. This is relatable to the previous three narrations which contain three daily life activities of millenial males. Without a sufficient supply of nutrition, the millenial males are, in this narration, implied to not able to perform the activities which make them appear masculine and the only way to gain the neccessary nutrition is by consuming L-Men. In summary, the narrations imply that millenial males are considered masculine if they appear to care about their appearance, responsible, and confident.

\section{Verbal Expressions That Project Masculinity in The Second Video Advertisement}

The first video advertisement, entitled "Iklan L-Men 2014 Versi Albert Sultan", has five different kinds of narrations which give an implication of masculinity which are as follows;

1. "Gak apa-apa, Ton" (It is okay, Ton)

2. "Dulu gue juga sekerempeng itu" (I was also as skinny as you before)

3. "makanya gua kencengin latihan" (that is why I increase the intensity of my exercise)

4. " "minum L-Men Gain Mass setiap hari" (drink L-Men everyday)

5. "jadi tak terkalahkan, invincible" (becoming unbeatable and invincible)

The choice of words in the second video advertisements seem to give the male viewers a lot of encouragement to build their body to the masculine shape. This can be seen from the use of "Gak apa-apa" (It is okay) and "Dulu gue juga sekerempeng itu" (I was also as skinny as you before). These two narrations are indirectly telling the viewers that for now it is fine to be skinny. However, in this context being skinny is actually not okay and the advertisement is just giving the viewers reassurances that they can change. This can be seen from the second 
narration that is "Dulu gue juga sekerempeng itu". "Dulu" (before) in Bahasa Indonesia refers to the past. The fact that this word is used is because it signifies that the person saying this has changed. In this context the change was from skinny body to a more muscular body. The third and fourth narrations are the suggestions from the advertisement to be emulated by the viewers who aspire to get their muscular body which is considered masculine. The suggestion to become masculine can be seen from the use of word "latihan" (exercise) which refers to an act of training one's body muscles. Not to mention that the fourth narration says "minum L-Men Gain Mass setiap hari" which, combined with the narrations before this, gives an implication that drinking L-Men everyday helps build body muscles. Thus, with the constant mentions and suggestions of possessing a muscular body, it can be concluded that what is considered masculine in this second video advertisement is having a strong muscular body.

\section{Non-verbal Expressions That Project Masculinity in The First Video Advertisement}

There are several images which can project the idea of masculinity in the first video which is masculinity based on the aesthetical appearance of millenial males. These can best be summarized up in the three figures below.

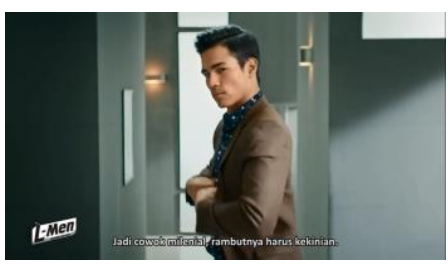

Figure 1.3

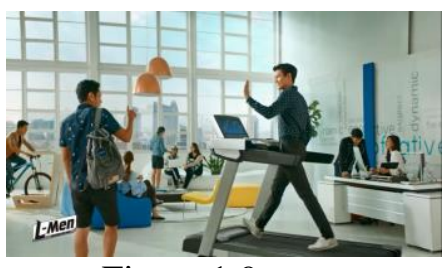

Figure 1.9

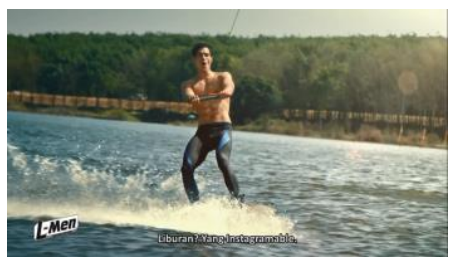

Figure 2.4

In figure 1.3, a male actor can be seen wearing a brown formal wear. According to Cerrato, the color brown denotes masculine qualities $(2012$, p. 3). In this figure, positioning plays an important role to show male's masculinity from his appearance. In the image, the male actor is shown quite far from the viewers. This is measured by how much his body seen in the image, in this case his upper body, face, and clothes are mostly seen. Thus, the image is trying to give an emphasis on how he dresses himself which gives an implication that a millenial male's choice of clothing can make him look masculine. Figure 1.9 employs several colors which denotes masculinity. First of all, two male actors are depicted wearing blue shirts which said color is implied to be the masculine color (Cerrato, 2012, p. 11). Secondly, yellow also present in the image. Yellow is thought to be the color that generates muscle energy (Cerrato, 2012, p. 7). This usage of yellow fit the image as the actor is portrayed walking on a treadmill which functions to strengthen the muscles on legs. On a subject of muscles, men nowadays appear to be harboring 'muscle dysmorphia' where they think that women prefer men with big muscles (Harrison, 2008 , p. 70). Thus, it is normal nowadays that millenial males are building their muscles for the sake of appearing masculine to the females. Figure 2.4 shows the male actor water-skiing in the sea. The sea can be understood as something that is dangerous and the fact that the actor is water-skiing there gives an implication of a man that loves challenges. Thus, figure 2.4 shows that confidence is one of the factor which will make males to appear masculine. The fact that the actor is shown showing his muscles gives a good indication that indeed masculinity in this first video advertisements comes the aesthetical appearance of the millenial males.

\section{Non-verbal Expressions That Project Masculinity in The Second Video Advertisement}

The second video advertisement tells the viewers that what is consideres as masculine is having a strong muscular body. This implication can be seen in several figures below. 


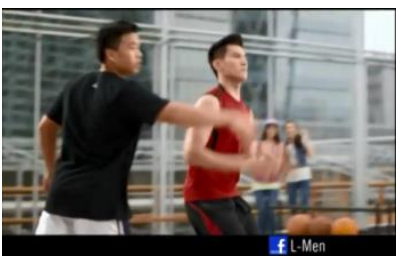

Figure 3.0

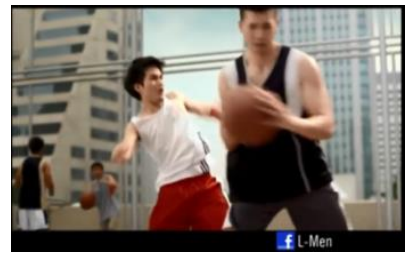

Figure 3.1

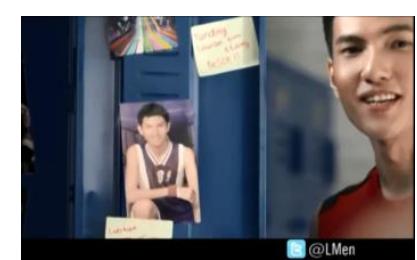

Figure 3.3

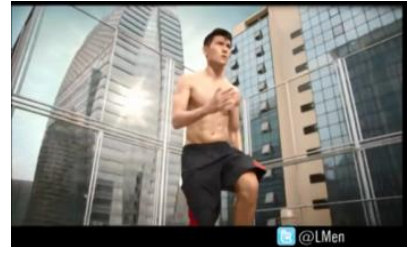

Figure 3.5

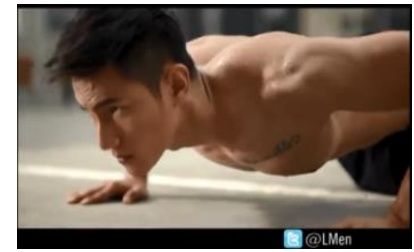

Figure 3.7

In figure 3.0 and 3.1 there are two depictions of men, one that is strong who is seen in figure 3.0 wearing red and one that is weak who is seen wearing white in figure 3.1. The actor in figure 3.0 is wearing red color, a color that represents strength and power, (Cerrato, 2012, p. 4), which are the qualities which this advertisement deems as masculine. The actor in figure 3.1, meanwhile, wears white which represents the loss of these masculine qualitites. Thus, the advertisement is using this distinction to lead its male viewers to believe what is masculine and what is not masculine. The masculine representation carried by the actor in red is also used to encourage the viewers who want to become masculine into emulating what he does. This is best explained by the positioning of the actor in figure 3.3. In this figure, the actor is seen on the right hand side of the scene while in his left is his past photo which shows how skinny he was. The positioning on the left marks as a "point of departure", while the positioning on the right marks the "new one which viewers must pay special attention to" (Kress \& van Leeuwen, 2006, p. 181). In this case, the "point of departure" is the actor's photo of his past when he was skinny and the "new" is him right now when he is strong and muscular. Thus, this positioning implies an encouragement to males to make them trying to be masculine. This encouragement and idea that masculinity is based on men's muscular body is determined in figure 3.5 and figure 3.7. In figure 3.5 and 3.7, the actor in red is now depicted shirtless to give an emphasis on his muscular body, which is considered to be masculine in this advertisement. Furthermore, he is shown exercising which is a way to make one's body to possess or gain more muscles. In conclusion, the masculinity in the second advertisement is indeed based on men's strong muscular body.

In summary, these two advertisements are able to project their own idea of what is masculine through the use of verbal and non-verbal expressions. The first video is intended to be "consumed" by the younger millenials and as such the wording and the choice of "masculine depiction" are activities and phrases which are common among younger millenials. Meanwhile, the second video is perhaps intended to be "consumed" by most male teenagers who want to be accepted by the society as men. Thus, the wording and actions in the second advertisements are mostly examples, encouragements and advices. 


\section{CONCLUSION}

In conclusion, the researcher found out that advertisements do promote their products using semiotic resources. Using these semiotic resources, the producers are able to make the advertisements appealing to the needs of their target market. This can be seen from the two L-Men advertisements entitled "L-Men 2018: 2Go \& Gain Mass: Men's Guide" and "Iklan L-Men Gain Mass Terbaru 2014 Versi Albert Sultan". The 2018 L-Men advertisements are targeted to the young millenial males and thus the semiotic resources in that advertisement copies the value of millenials. Meanwhile, the 2014 advertisements are targeted to male teenagers who want to be seen as masculine. As such, the semiotic resources in the 2014 advertisements are appealing to their needs by giving them encouragement in their quest to become masculine.

\section{REFERENCES}

Cerrato, H. (2012). The Meaning of Colors. Retrieved from Hermancerrato.com: http://hermancerrato.com/graphic-design/images/color-images/the-meaning-of-colorsbook.pdf

Cook, G. (2001). The Discourse of Advertising. New York: Routledge.

Danesi, M. (2004). Messages, Signs, and Meanings: A Basic Textbook in Semiotics and Communication Theory Third Edition. Toronto, Ontario: Canadian Scholars' Press Inc.

Ellemers, N. (2018). Gender Stereotypes. Annual Reviews of Psychology, 276-291.

Elliott, R., \& Elliott, C. (2005). Idealized Images of Male Body in Advertising: a ReaderResponse Exploration. Journal of Marketing Communication.

Kress, G. (2010). Multimodality: A Social Semiotic Approach to Contemporary Communication. New York: Routledge.

Kress, G., \& van Leeuwen, T. (2006). Reading Images. London: Routledge.

Schreier, M. (2012). Qualitative Content Analysis in Practice. London: SAGE. 